DEVELOPMENTAL BIOLOGY 19, 12-40 (1969)

\title{
Cellular Differentiation and Pattern Formation during Metamorphosis of the Milkweed Bug Oncopeltus ${ }^{1}$
}

\author{
Peter 4 . Lawrence \\ Departments of Biology, University of Virginia, Charlottesville, Virginia, \\ Western Reserve University, Cleveland, Ohio, and Department of \\ Genetics, Milton Road, Cambridge, England
}

Accepted September 27, 1968

\section{INTRODUCTION}

This paper is concerned with the metamorphosis of epidermal cells in an insect. While in Diptera metamorphosis is so extreme that the cells of the adult arise from localized pockets of embryonic cells that are sequestered in the larva, in Hemiptera larval cells may transform directly into adult cells without intervening cell division (Wigglesworth, 1934; Lawrence, 1966b). Cellular differentiation is a process during which the synthetic functions of a cell change and which is usually accompanied by a restriction of developmental plasticity (Grobstein, 1959). I have proposed (Lawrence, 1966a) that by these and other criteria the striking changes in the cytological appearance and secretions of the hemipteran epidermis at metamorphosis are equivalent to those which characterize other examples of cell differentiation.

The insect offers two main advantages in a study of cell differentiation. First, the process is under the control of a single hormone; and second, each cell secretes a piece of cuticle which is an indicator and permanent record of its syntheses (Wigglesworth, 1940a). In Oncopeltus, in addition to the changes that affect each cell during metamorphosis, there is also an interaction between the epidermal cells which leads to the determination of an evenly spaced minority as hair mother cells; these subsequently develop into evenly spaced hairs (Lawrence, 1966b). The epidermis provides good material for a study of both cell differentiation, as witnessed in the changing biochemical functions of the cells, and pattern formation, as exemplified in the

${ }^{1}$ Present address: Department of Genetics, Milton Road, Cambridge, England. 
ordered development of the hairs. This paper examines the effects of a synthetic juvenile hormone analog on these processes in Oncopeltus. Some of the results have been published in preliminary form (Lawrence, 1967).

\section{MATERIALS AND METHODS}

Oncopeltus fasciatus Dall were taken from the culture kept for many years in the Department of Zoology, Cambridge, and reared as previously (Lawrence, $1966 \mathrm{~b}$ ) at $29 \pm 0.5^{\circ} \mathrm{C}$. Whole mounts of integument were fixed in Carnoy's fluid and stained for about 30 seconds in Hansen's trioxyhematein. Some mounts were stained in Romanes' silver stain (cf. Wigglesworth, 1953). Exuviae were softened by boiling for 1 minute in a 3:2 mixture of isopropanol and water (Marcus, 1962).

Synthetic juvenile hormone was very generously provided by Professor Carroll M. Williams (Law et al., 1966; Romaňuk et al., 1967). This juvenile hormone analog in a crude extract was made up to concentrations of $5 \mu \mathrm{g} / \mathrm{ml}$ and $0.25 \mu \mathrm{g} / \mathrm{ml}$ in propylene glycol and $0.25 \mu \mathrm{l}$ (containing 1.25 and $0.06 \mu \mathrm{g}$ of the extract) was injected through one leg or applied to the tergites; $0.25 \mu \mathrm{l}$ of pure propylene glycol had no discernible effects on injected 5th-stage larvae. All insects survived the injections. Mitomycin $\mathrm{C}$ was dissolved in insect Ringer.

\section{RESULTS}

\section{The Normal Metamorphosis}

For simplicity, the metamorphosis of only two integumental areas, the central part of the third sternite and an area of the third tergite immediately anterior to the opening of the stink gland, which is marked as a black spot in larvae, will be described in detail. The characteristics of these areas in larvae and adults are tabulated for comparison (Figs. 1-4).

The bristles, which are distributed fairly uniformly over the surface of the larval insect, serve as mechanoreceptors. In the adult, in addition to bristles, a dense mat of noninnervated hairs develops. The development of these structures has been described previously (Lawrence, 1966b). Figure 5 summarizes the course of events during the metamorphic molt. As the animal feeds, it swells up and the epidermal cells become more sparse. Proliferative divisions follow, beginning in the intersegmental membranes and spreading over the rest of the 


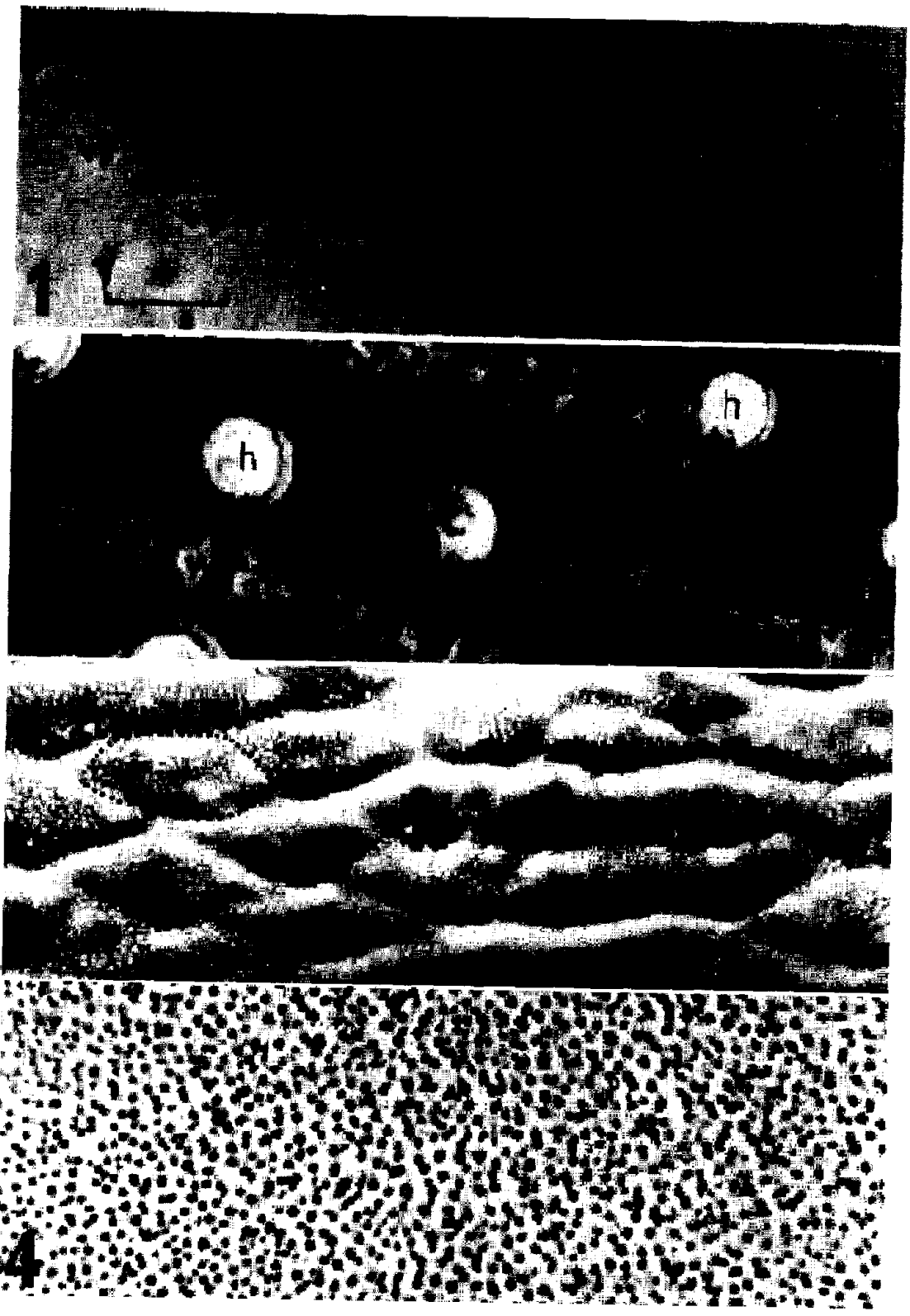

FIGs 1-4. Whole mount of cuticle photographed under phase contrast. $Y$ I400; scale $=10 \mu$. 
TABLE 1

The Integument of Two Areas of Oncopellus ix Larvae and Adults

\begin{tabular}{|c|c|c|c|c|c|}
\hline Area & Group & $\begin{array}{l}\text { Cutiele } \\
\text { strueture }\end{array}$ & Melanin & & $\begin{array}{l}\text { Fig. } \\
\text { no. }\end{array}$ \\
\hline \multirow[t]{2}{*}{ 3rd sternite } & Larval & Smooth & Absent & Bristles & 1 \\
\hline & Adult & $\begin{array}{l}\text { Smooth (central), } \\
\text { tubereles (lateral) }\end{array}$ & Present & Bristles + hairs & 2 \\
\hline \multirow[t]{2}{*}{ 3rd tergite } & Ixarval & Smooth & Present & Bristles & 3 \\
\hline & Adult & Tulsercles & Absent & Very few bristles & 4 \\
\hline
\end{tabular}

abdomen (Wigglesworth, 1940b; Lawrence, 1968). During the molt cycle three kinds of organs develop from epidermal cells: the chemosensilla appear extremely early and their differentiative divisions can be seen a few hours after the previous ecdysis. During the early phase of proliferative cell divisions some new bristles develop on the ster-

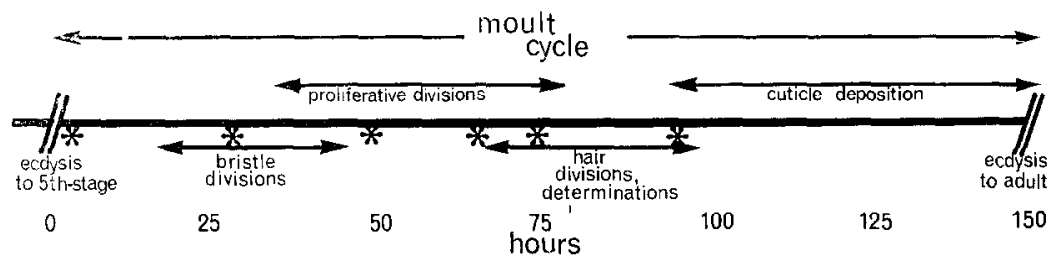

Frg. 5. Events in the last molt of Oncopeltus. Asterisks mark times of juvenile hormone injection in the experimental series.

nites, but on the tergites the majority of bristles degenerate. Later the special cell divisions concerned in hair genesis begin and only cease when the new cuticulin layer is initiated (Lawrence, 1966b). The amount of proliferative cell divisions is quite different in the metamorphic molt from that in the larval molt, and as a result the cell density in a late 5th-stage larva is much lower than that in a late 4thstage larva. Apart from the gross changes in the integument resulting

Fig. 1. Cuticle from the third larval sternite. Note that it is both transparent and relatively smooth. There are no hairs.

FIG. 2. The same area as Fig. 1, but in the adult. Note the dense, evenly distributed hairs $(h)$. The cuticle is black, owing to the deposition of melanin.

FIG. 3. The black, smooth cuticle of the larval third tergite. The small white spots are pore canals. The dotted boundary line demarcates the cuticle secreted by a single cell.

FIG. 4. The adult tergite. Note the absence of black pigment and the uniform distribution of vertically oriented tubercles. 
from metamorphosis, the timing of the molt is altered: the larval molt lasts 90 hours, whereas the metamorphic molt, 150 hours.

These changes are the result of the lack of a single morphogenetic agent, juvenile hormone (Wigglesworth, 1934). In order to analyze the process of metamorphosis potent quantities of a synthetic juvenile hormone analog were injected at various times during the molt and the results examined.

\section{Complete Effect--the 6th-stage Larva}

When $1.25 \mu \mathrm{g}$ of synthetic juvenile hormone was injected into 5thstage larvae (weight $=30 \mathrm{mg}$ ) within 10 hours of ecdysis metamorphosis was almost completely inhibited. The insects molted at approximately 95 hours and in about $30 \%$ of the cases underwent successful ecdyses, becoming 6th-stage larvae of characteristic form (Novák, 1951). They grew and fed as normal larvae, and often molted into 7th-stage adults which, although larger than normal, were perfectly formed; sometimes 7th-stage intermediates resulted. In all respects listed in Table 1 and in many others, these insects were completely larval; however, the chemosensilla, which are normally found in abundance only in adults, developed as in a metamorphic molt. In the remaining $70 \%$ of the cases the insects failed to extricate themselves successfully from their exuviae although microscopic examination showed them to be perfect 6th-stage larvae.

This potent quantity of juvenile hormone was then injected into batches of insects at $27,49,64,74$, and 96 hours after ecdysis and the cffccts werc recorded. These effects will be described in order. In addition injections of a smaller quantity of juvenile hormone $(0.06 \mu \mathrm{g})$ were made into groups of insects at 5 hours and at 64 hours after ecdysis. This amount of juvenile hormune never caused the development of perfect 6th-stage larvae.

\section{Effects on the Time of Ecdysis}

Insects injected with juvenile hormone attempted ecdysis much earlier than the controls, which molted at about 150 hours. The earlier the juvenile hormone was injected, the more precocious was the attempted ecdysis. The 6th-stage larvae emerged only about 96 hours after the previous ecdysis. No insects injected at 27,49 , or 64 hours successfully cast their exuviae, but they began ecdysis at times intermediate between 96 and 150 hours. Of 20 insects injected at 74 hours, 
all attempted ecdysis before the first of the 20 controls, but only about half emerged successfully. Although the ecdysis was marginally advanced by injection of juvenile hormone at 96 hours, ecdysis was always successful and perfect adults emerged.

Injection of $0.06 \mu \mathrm{g}$ of juvenile hormone had little effect on the length of the molt cycle; indeed, this was somewhat extended even by injection at 5 hours after the previous ecdysis.

\section{Effects on the Individual Cell}

The cells are not determined irrevocably to produce adult cuticle until the formation of that cuticle has already begun at 96 hours. Before that time juvenile hormone does affect the type of cuticle they form. Injection of $1.25 \mu \mathrm{g}$ at 27 and 49 hours ensured that all the epidermal cells produced perfect larval cuticle. However treatment at 64 and 74 hours had a much more variable effect. In any particular insect all the epidermal cells of the abdomen responded uniformly (Figs. 6-9) and each secreted a cuticle which combined some adult and some larval features. The tergal cuticles of different individuals could be arranged in a continuous series of intermediates from larval to adult, of which Figs. 6-9 illustrate examples. These cuticles are clearly formed by cells which are neither adult nor larval, and such cells will be referred to as intermediate cells. Adult and larval bristles can be distinguished from each other (I awrence, 1966a). Juvenile hormone injected as late as 74 hours in the molt caused some larvalization of the bristles, so that intermediate adult/larval structures were also secreted by the bristle cells. There was no asymmetry of effect with respect to the side of injection, suggesting that the factor preventing complete inhibition of metamorphosis was not availability of juvenile hormone, but the lability of the cells, at the time of treatment.

When a smaller quantity of juvenile hormone $(0.06 \mu \mathrm{g})$ was injected at 5 hours the insects did not molt prematurely and usually emerged successfully. They had the appearance of perfect adults with fully developed wings and genitalia, but closer examination revealed that the hormone had affected the epidermis, particularly on the injected side. The tergal cuticle was often a mosaic of different cell types: some cells made completely larval cuticle others completely adult, and intermediate cells of many types were also found (Fig. 10). 


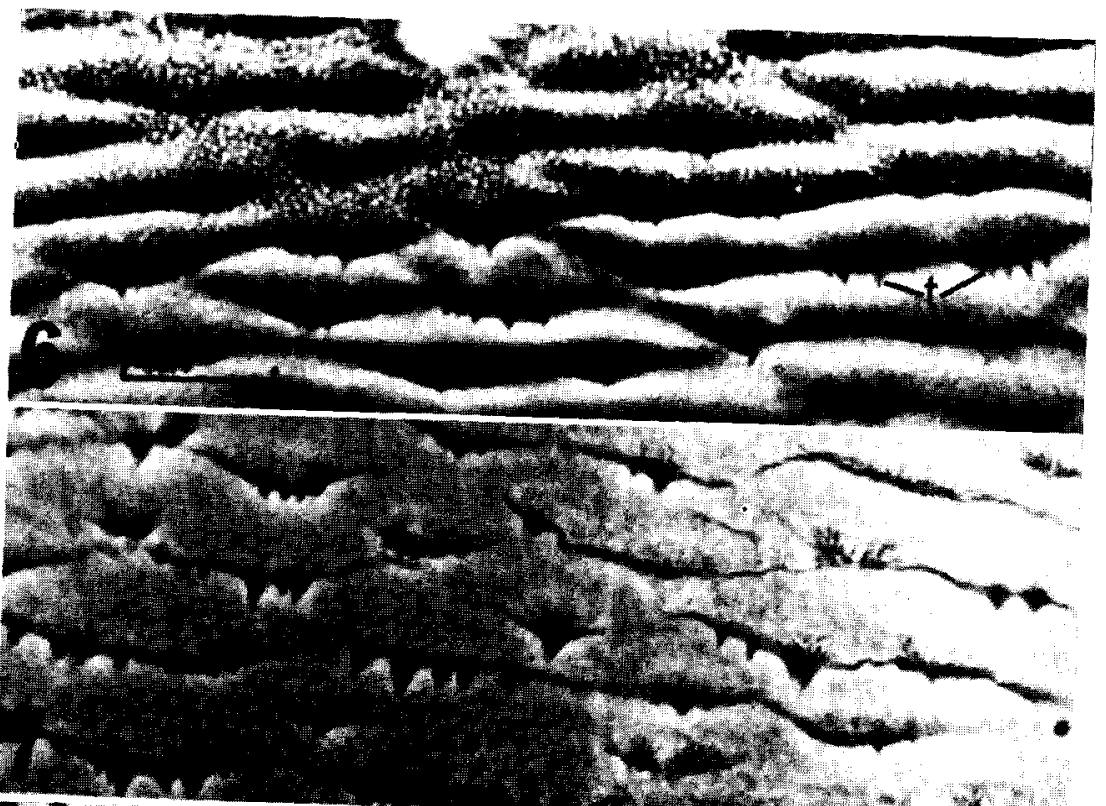

Core

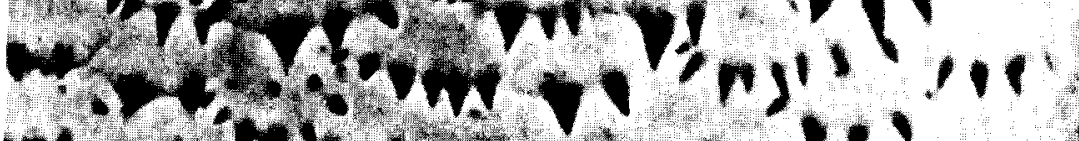

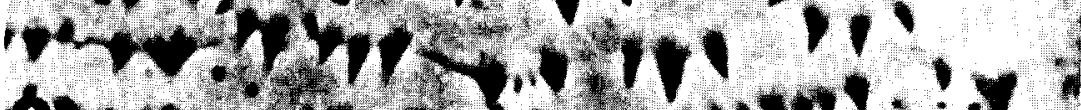

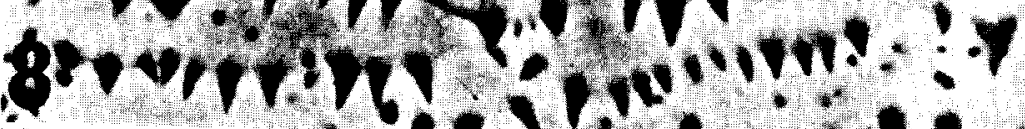
(1) . . .

- orsto

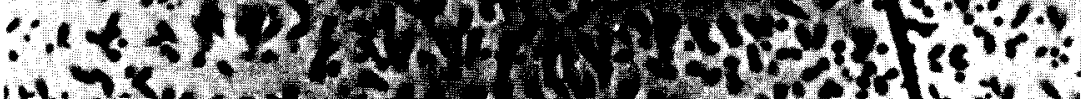

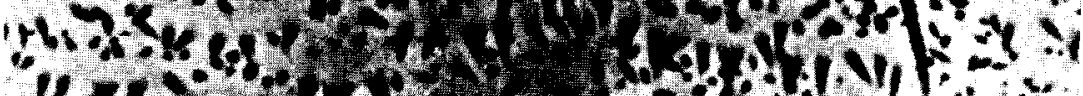

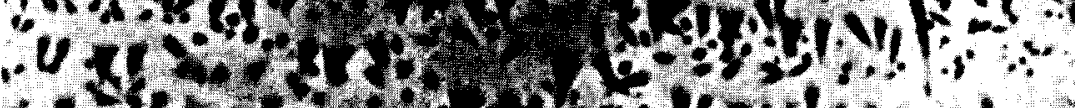

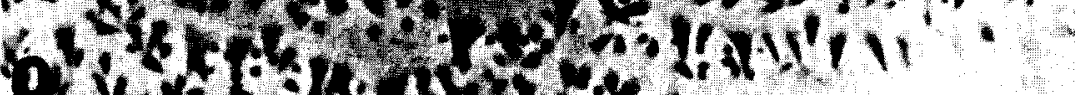

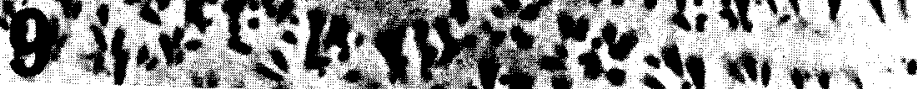

FIGs. 6-9. Phase contrast pictures of whole mounts of four examples of intermediates. $\times 1400$; scale $=10 \mu$. 


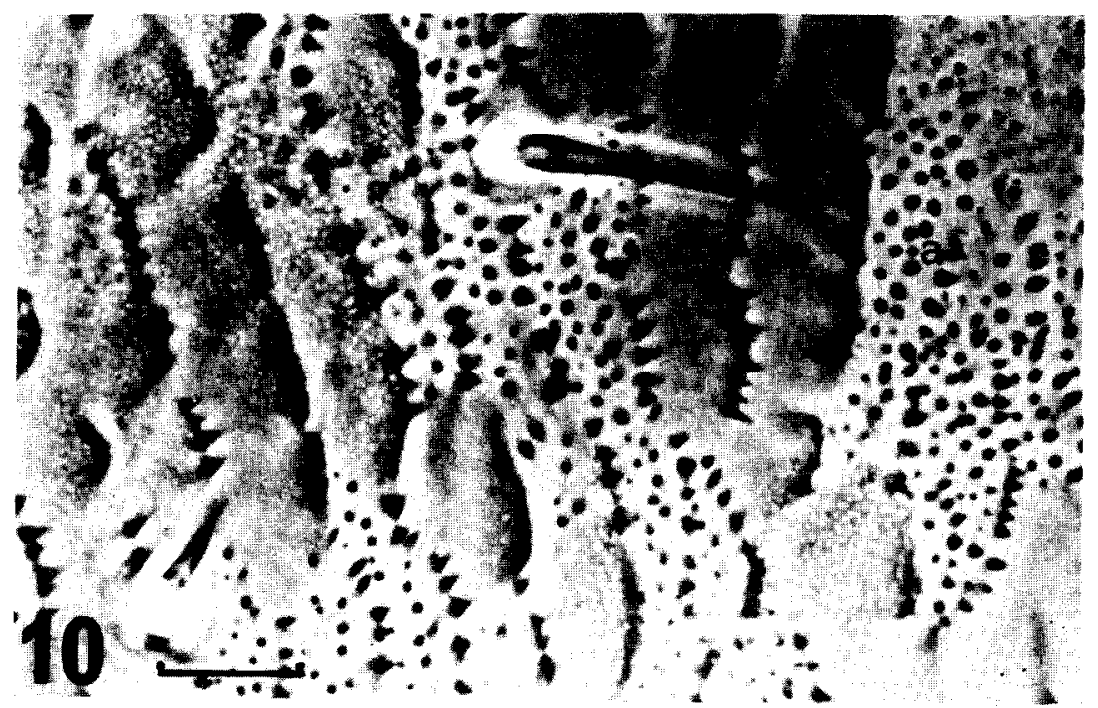

FIG. 10. At 5 hours after ecdysis, $0.06 \mu \mathrm{g}$ of juvenile hormone was injected. Note that the cells' response to the hormone is variable: some cells secrete perfect adult cuticle $(a)$, some larval $(l)$ cuticle, and others intermediate cuticle $(i)$.

The formation of tubercles was more sensitive to the juvenile hormone than the synthesis of pigment; for while cells secreting cuticle with adult pigmentation and larval microsculpture were common, the reciprocal kind of intermediate cells were never found. Clearly, these cellular capacities can function independently (Wigglesworth, 1940b). The same quantity of juvenilc hormone had little effect when injected at 64 hours after ecdysis, but occasionally some larvalization of the tubercles could be seen on the injected side only. Such a local effect of the juvenile hormone, and the lack of response of the molt cycle or the wings indicate that, in this case, in contrast to the situation when

Fig. 6. Tergal cuticle from intermediate resulting from injection with $1.25 \mu \mathrm{g}$ of juvenile hormone at 49 hours after ecdysis. Note presence of pigmentation, but some adultoid tubercles $(t)$; these are oriented within the surface plane of the culicle and nol uut of it, as in normal adults (compare Figs. 3 and 4 ).

Fig. 7. As Fig. 6, but injected at 64 hours. Note absence of larval pigmentation, and the greater development of tubercles.

Fig. 8. As Fig. 6, but injected at 64 hours; tubercles more advanced and some vertically oriented tubercles formed by the centers of the cells.

Fig. 9. As Fig. 6, but injected at 74 hours. An almost perfect adult, but compare Fig. 4. 


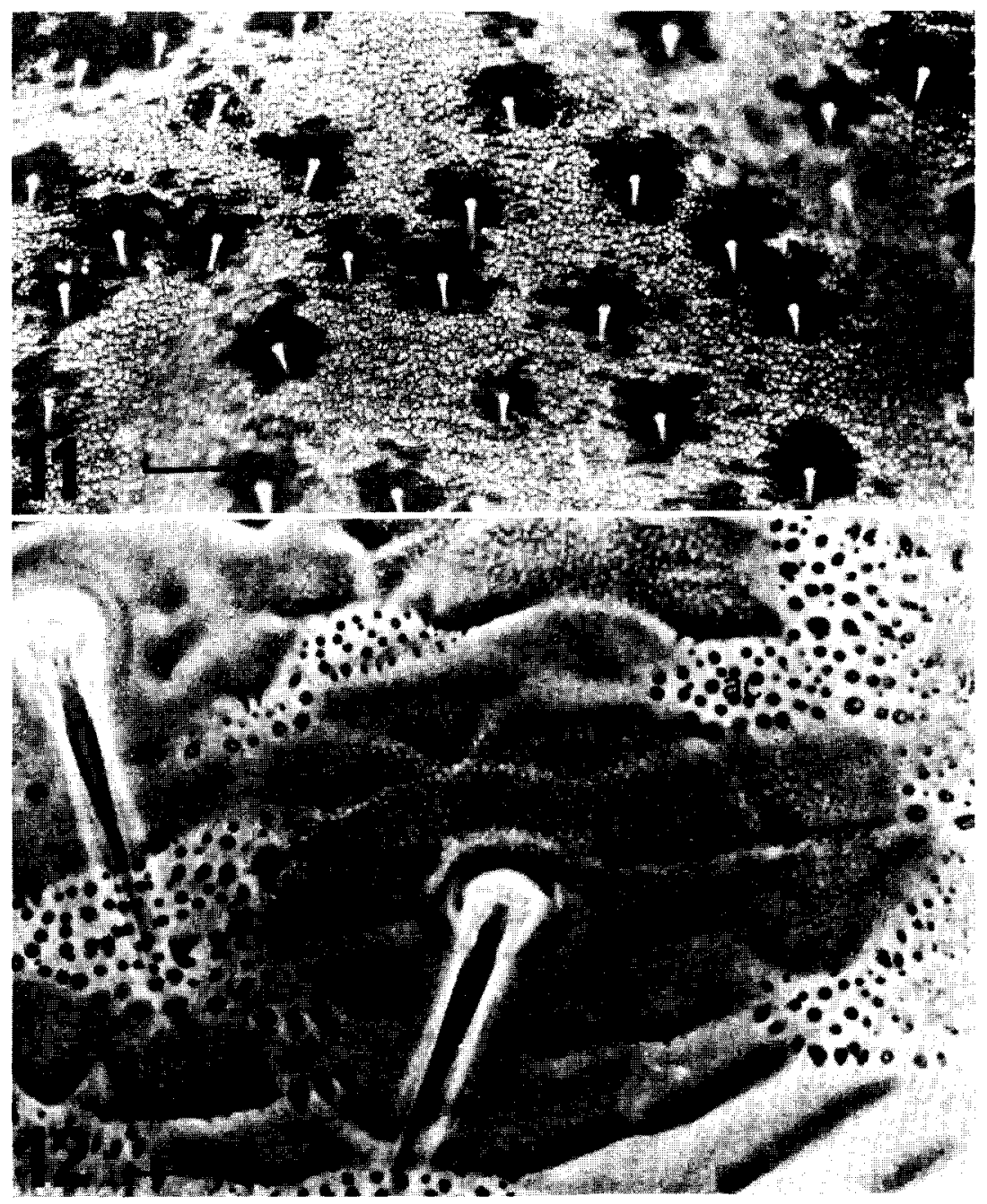

Frg. 11. Tergites of an intermediate insect resulting from topical application of juvenile hormone. Note how each bristle $(b)$ is surrounded by a smooth larval patch of cuticle. $\times 140 ;$ scale $=100 \mu$.

Fig. 12. A region of cuticle around a tergal bristle. Note (cf. Figs. 3 and 4) that near the bristle the cclls secrete larval cuticle $(l c)$, outside the cells form adult cuticle $(a c)$. Other cells form intermediate cuticle (ic) of the same type as is illustrated in Fig. 8. 
much more hormone was injected, the extent of the response may well be limited by the amount of juvenile hormone available.

The most striking examples of mosaic insects, with many different types of intermediate cells, were produced, not by injection, but by topical application of the juvenile hormone. This resulted in localized entry of the hormone through the hristle sockets (Fig. 11) (Wigglesworth, 1942, 1961); although the molt time was not influenced, a whole range of cell types from pure adult to pure larval coexisted in the same individual. Figure 12 shows such an insect which was adult in form, molted at about 150 hours, had normal adult wings and genitalia, but the integument was a mixture of cell types. Such mosaic insects serve to underline the essential independence of cellular metamorphosis from the timing of cuticle production; although all these cells worked together to produce an integrated cuticle, they secreted many different types of structure.

In summary: Juvenile hormone can still turn prospective adult cells into larval cells up until 50 hours after ecdysis, and between then and 96 hours has effects on the individual characters of these cells. Pigment production is influenced completely or not at all, whereas cuticular microsculpture can be affected partially.

\section{Effects of Juvenile Hormone on Hair Development}

The process of hair determination and development is amenable to analysis by injection of juvenile hormone. During a normal larval molt cycle in the presence of the hormone, no hairs are formed. During normal metamorphosis dense hairs develop on the sterniles as approximately 1 in 4 of the epidermal cells become determined as hair mother cells. The bristles are formed again by the selfsame cells and a small number of supplementary bristles develop, so that the adult pattern consists of more sparsely distributed bristles, evenly interspersed with numerous hairs (Fig. 14e). Hair development in the 5th-stage larva was completely suppressed by injection of $1.25 \mu \mathrm{g}$ of synthetic juvenile hormone analog at the very beginning of the molt. Later injection of the same quantity of hormone, while it completely inhibited metamorphosis of the epidermis as reflected in the larval cuticle that was formed, allowed development of a variable number of hairs (Fig. 13). Injection at 27 hours produced insects in which a small number of perfect adult hairs developed in an otherwise completely larval integument (Fig. 14b). 


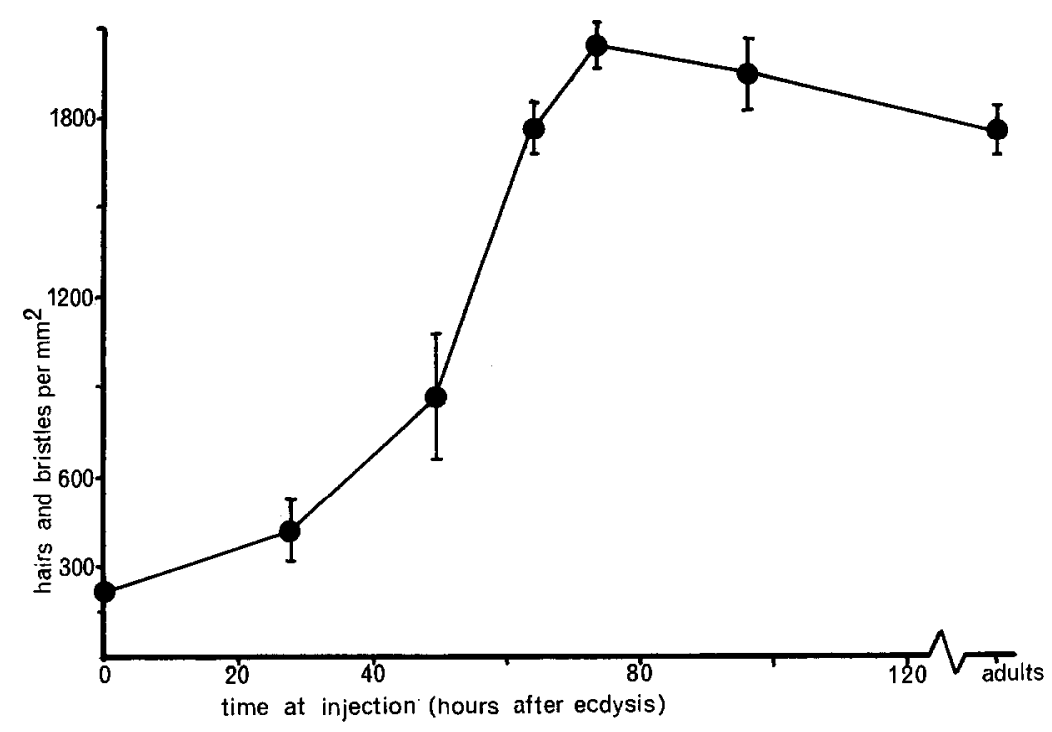

FIG. 13. Density of hairs and bristles in intermediates produced by injection of juvenile hormone at different times. The development of hairs is affected from 0 to 61 hours, but not afterward. The slight decrease in density of hairs in insects injected at 96 hours and in adults, is because these insects, unlike the intermediates, successfully cast their exuviae, and expand a little. Vertical lines demarcate twice the standard error of the means ( $\mathrm{SE}$ included within point for cases after injection at 0 hours).

Figures $14 \mathrm{a}$ and $14 \mathrm{e}$ contrast the pattern of hairs and bristles in the normal larva and adult. There is considerable rcgularity in the spacing of these structures, and moreover, in the adult pattern it is clear that the bristles and hairs are equivalent units in the pattern.

In order to assess the amount of uniformity in the spacing of hairs and bristles, the method of Clark and Evans (1954) was employed. These authors derived an expression $R$, which quantifies the uniformity of distribution of units in this kind of pattern. $R$ takes values within the limits $0 \leqslant \boldsymbol{R} \leqslant 2.1941$ and is equal to $2 \bar{r} \sqrt{p}$, where $\bar{r}$ is the mean distance of the units from their nearest neighbors, and $\rho$ is equal to the density of the units. When $R$ lies between 0 and 1 the units are clustered, when equal to 1.00 the units are randomly distributed, and as it approaches its upper limit the distribution becomes more uniform. The distribution of bristles and hairs in Oncopeltus is always better than 1, which implies that the location of these units is under some 

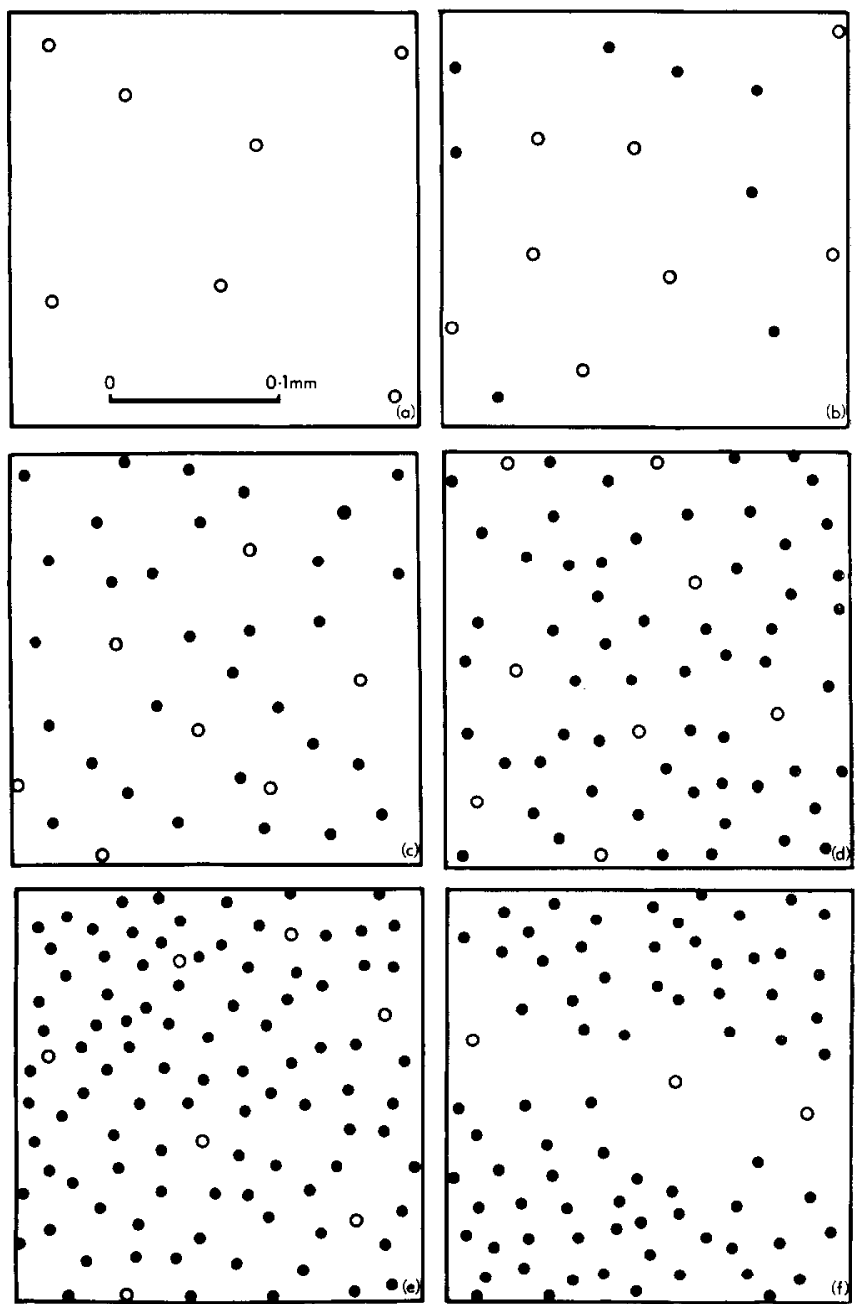

Fig. 14. The distribution of bristles (open circles) and hairs (filled circles) in the central part of the third sternite of a larva (a), an adult (e), and three intermediates produced by injection of juvenile hormone at 27 hours (b) and 49 hours ( $c$ and $d$ ). Also illustrated $(f)$ is the distribution after topical application of juvenile hormone and its local penetration through the bristle sockets. From Lawrence (1967). Parts a-f all to same magnification. 
regulatory control. During metamorphosis the siting of new hairs depends on the extant bristles, and in fact $R$ for adults $(1.70 \pm 0.02)$ is higher than for larvae ( $R=1.48 \pm 0.01)$.

Also illustrated (Figs. 14b,c, and d) are examples of three intermediates bearing different densities of hairs, produced by injection of juvenile hormone at 27 and 49 hours after ecdysis. It is apparent that the hairs which do form in these intermediates are not random samples of the hairs which would have developed in the normal adult. A plot of the relationship between the measure of distribution $R$, and the density of hairs and bristles in different intermediates (Fig. 15) shows that the uniformity of distribution improves with density $(p<0.001)$. Moreover, the simulation described on page 26 shows that if intermediates were formed by adding a random sample of hairs from an adult pattern, then the uniformity of distribution would suffer in many of the intermediates and $R$ could fall to as low as 1.17 .

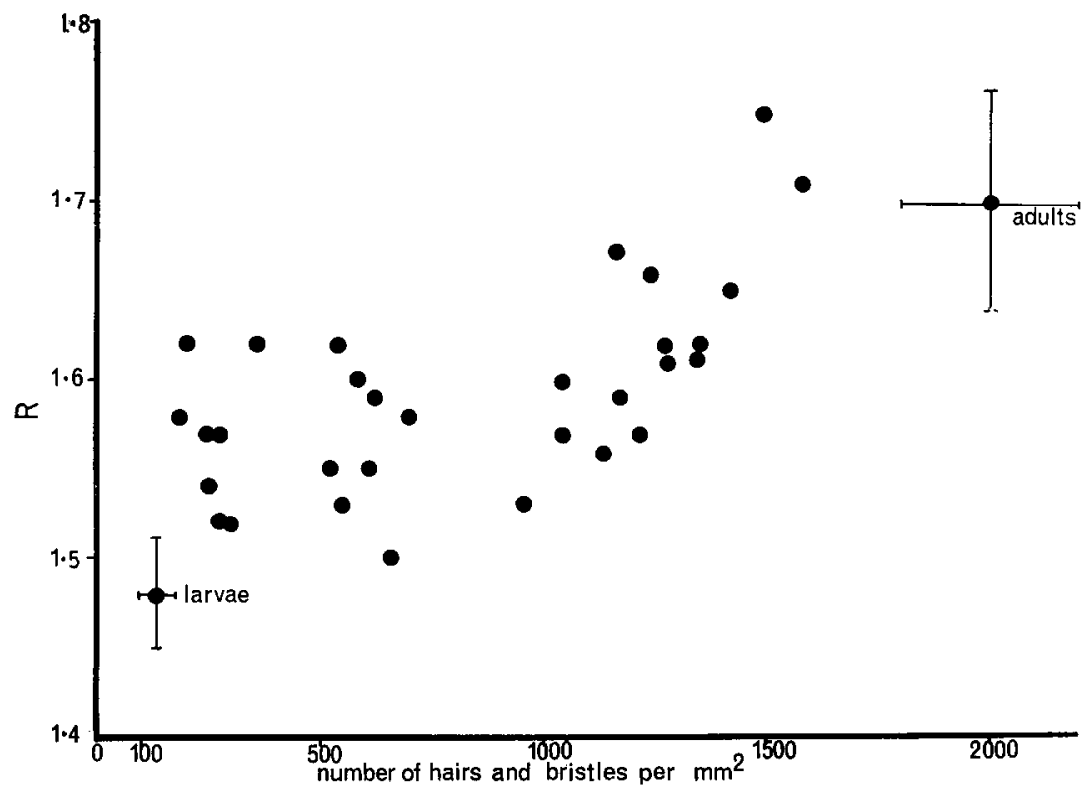

FIG. 15. The relationship between uniformity of distribution $(R)$ and hair and bristle density in adults, larvae, and intermediates. The intermediates were produced by injection of $1.25 \mu \mathrm{g}$ of juvenile hormone at 27 and 49 hours. Note that the uniformity of distribution increases with density: the slope bcing significantly greater than zero $(p<0.001)$. The vertical and horizontal lines demarcate two standard deviations. 
When $0.06 \mu \mathrm{g}$ of juvenile hormone was injected at 64 hours, the distribution or density of hairs was unaffected. However, injection of the same amount of juvenile hormone at 5 hours after the ecdysis, restricted the development of hairs. It has been noted above that this lower quantity of hormone produced an integumental mosaic for adult, larval, and intermediate patches. The hair distribution reflected this heterogeneity; closely packed hairs developed in the adult regions, and sparse hairs in the larval areas. The measure of distribution, $R$, fell to as low as 1.15 in some individuals.

\section{Topical Application of Juvenile Hormone}

When the synthetic juvenile hormone analog is smeared onto the surface of the insects, it enters the epidermis through the bristle sockets; if low quantities are used, it has a local effect. The bristles develop in the larval form, and the adjacent integument becomes larval by all the criteria, and lacks hairs. Between these patches of larval tissue, the normal adult hair pattern develops (Fig. 14f). These individuals molt at about 150 hours, have fully formed wings and genitalia, and are fertile.

\section{Mitomycin $C$}

Mitomycin was injected because of its inhibitory effects on DNA synthesis and mitosis, relative lack of toxicity in insects, and because cell divisions have been implicated in the response of cells to juvenile hormone (Piepho, 1939; Lawrence, 1966a; Sehnal and Novák, 1966). Mitomycin injected in large doses of $50 \mathrm{\mu g} / \mathrm{gm}$ at the beginning of the molt cycle had drastic effects on the epidermal cells, many of which died while the survivors became enormous. This epidermis still secreted a cuticle, and the insects were not killed. 'The bristle cells, which do not divide or undergo DNA synthesis, were completely unaffected. Hair development was drastically curtailed, just as in wounded tissue (Wigglesworth, 1940a; Lawrence, 1966a). Smaller doses (5-10 $\mu \mathrm{g} / \mathrm{gm}$ ) injected early delayed cell divisions and molting for about 2 days, although there was little evidence of cytological damage. This dose was injected during the differentiative divisions concerned in hair formation, at 70 hours after ecdysis. On the injected side, hair development was severely curtailed, presumably due to the direct effect of the antibiotic on these divisions; there was no effect on the bristles. Hairs seemed to be removed haphazardly, 


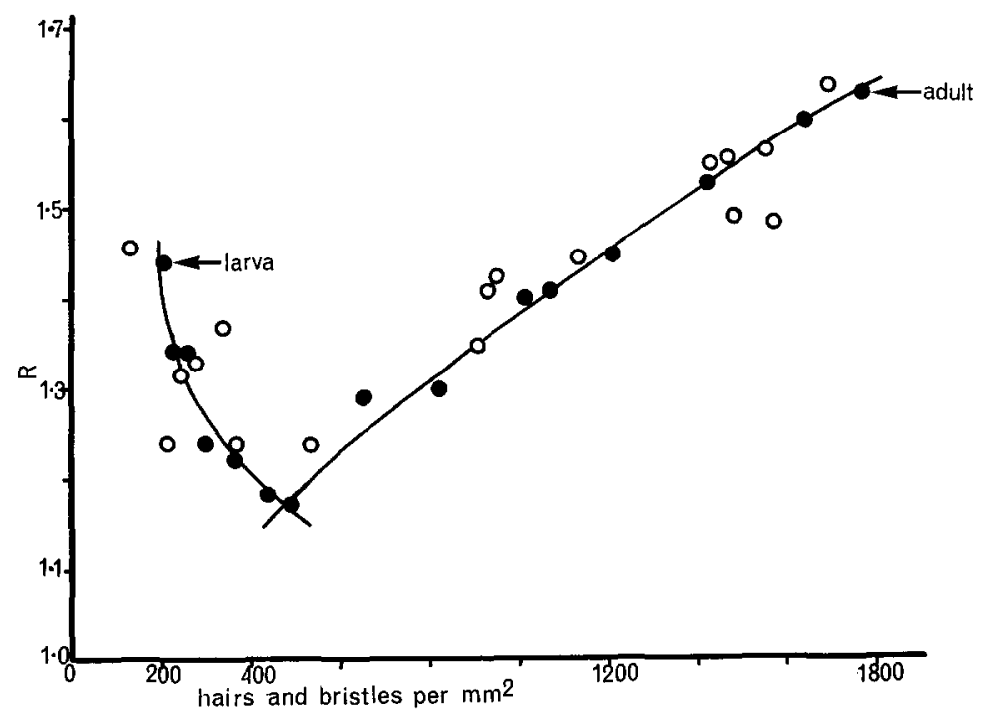

FIG. 16. The relationship between uniformity of bristle and hair distribution $(R)$ and their density during random removal of hairs from a complete adult pattern: filled circles, simulation; open circles, corresponding regions of adult bugs treated with mitomycin $\mathrm{C}$ at 70 hours.

and the distribution as measured by $R$ suffered and fell as low as 1.24 in some individuals (Fig. 16). Other insects had only bristles on the injected side, their bald appearance being reminiscent of the scaleless adults of Antheraea produced by Krishnakumaran et al. (1967) with the same agent.

In order to test the impression that mitomycin removed hairs at random from the adult pattern, such a system was simulated. A real adult pattern was drawn with the camera lucida, and found to have an $R$ of 1.63. All the hairs, but not the bristles, were numbered. Hairs were removed in batches with the aid of a table of random numbers, and the $R$ was measured and plotted against density (Fig. 16). As the density decreases the curve falls to a low of $R=1.17$; then as the density falls still further the relatively uniform distribution of the bristles begins to reappear, and $R$ rises until, at a value of 1.43 , all the hairs have been removed and the distribution of the bristles alone is measured.

The figures for $R$ and density taken from insects treated with 
mitomycin were also drawn on the graph and can be seen to fit very well. This simulation thus supports the impression that mitomycin effectively removes the hairs at random from established adult pattern. Mature bristles are unaffected. It seems unlikely therefore that mitomycin removes mature hairs; rather it disrupts the development of new hairs, suggesting that the pattern is already established before completion of hair development.

As the mitomycin affected only the injected side, some insects were treated with both juvenile hormone and mitomycin at about 60 hours after the ecdysis. After the next molt the insects were freed from their exuvia, and the new cuticle was examined. It was found that both sides showed larval characters in the integument to the same extent, except that only the injected side had any substantial reduction in hair number. This result suggests that the juvenile hormone and the antibiotic have independent effects on hair development and that the mitomycin acts much later than the hormone.

\section{DISCUSSION}

\section{Effects of the Juvenile Hormone on Individual Cells}

Wigglesworth (1940b) reported that, as the last molt cycle of Rhodnius progressed, the response of the epidermal cells to juvenile hormone waned. It was impossible to inducc perfect 6th-stage larvae when the parabioses were performed after the beginning of the proliferative divisions.

Moreover he described the formation of intermediate types of cuticle by single cells, and showed that features of adult and larval cuticle could be influenced independently in the same cell. These results also apply to Oncopeltus.

Wigglesworth also noted that there was some temporal correlation between the response of cells to the juvenile hormone and their divisions. Areas of integument in which early cell division occurred lost their responsiveness to the juvenile hormone before other areas. Rather similar results have been reported by Sehnal and Novák (1966) for the larval-pupal molt of Galleria, which have led these authors to propose that cell division is critical to the process of cellular metamorphosis. Indeed, wounded and dividing cells of Iarval Lepidoptera respond to minute quantities of juvenile hormone, and remain larval while the rest of the insect metamorphoses (Piepho and Heims, 1952; 
Schneiderman and Gilbert, 1958). The present experiments on Oncopeltus, while they are not inconsistent with the thesis that the epidermal cells respond particularly at mitosis to the juvenile hormone, do show that the cells are sensitive at other times. General effects on all the epidermal cells can be obtained at 74 hours, when most of the proliferative divisions have been completed, and when it is far too late to influence development of hairs whose differentiative divisions have just begun. Moreover, experiments with mitomycin where cell divisions are inhibited on one side of the sternites only, and yet the injected juvenile hormone affects both sides evenly, do not support this idea.

The continuous series of intermediate types of cuticle resulting from injection of potent doses of juvenile hormone at different times in the molt cycle (Figs. 6-9) show that during the period 49 to 74 hours after ecdysis, the epidermal cells' synthetic functions, as assayed by the type of cuticle they secrete, are becoming gradually committed to the adult pattern. Treatment with juvenile hormone during this process results in cells which share larval and adult features.

Such intermediate cells have been described before, not only as caused by hormonal balance (Wigglesworth, 1934), but also by genetic effects such as the mutant Hairy wing in Drosophila (Lees, 1942), or in certain kinds of intersexes when bristles, secreted by single cells, are intermediate between normal male and female bristles (Hollingsworth, 1964; Stern and Mukherjee, 1964; Hildreth, 1965). The male genital disk of Drosophila, normally bearing two fields of distinct bristles, can be bisected, cultured for a time in vivo, and then forced to metamorphose by implantation into a fully grown larva. If metamorphosis occurs before regulation is complete, bristles of intermediate structure are formed in areas intervening between fields of the two bristle types (Lüönd, 1961). During experimentally induced reversal of metamorphosis in Oncopeltus, when repeated divisions of adult cells gradually promote the recovery of the larval condition, bristles which are neither fully larval nor adult are commonly formed (Lawrence, 1966a). But cells are not usually intermediate for unit characters, such as pigment: Stern (1967) has reported that in intersexes of Drosophila, in an area melanized in the male but not in the female, there is a cellular mosaic of pigmented and unpigmented cuticle, just as in some regions of Oncopeltus intermediates (Fig. 10). A parallel between intersexes and intermediates was noted by Wiggles- 
worth (1936). Insect intersexes usually consist of a mosaic of differently sized areas of male and female cells, the sexual determination being made at various stages of development, and influenced by "nongenetic or even chance factors" (Seiler, 1965), and then being propagated in the daughter cells. In the experiments reported here, such a process of chance determination may have occurred when a small amount of juvenile hormone was injected at the beginning of the molt; in these experiments the hormone has shown a more pronounced effect on the injected side, and is probably therefore present in too small quantities to give unequivocal instructions to all the epidermal cells. At the imprecise borderline between tubercled and smooth cuticle on the normal adult sternite (Fig. 17) the cells secrete a cuticle

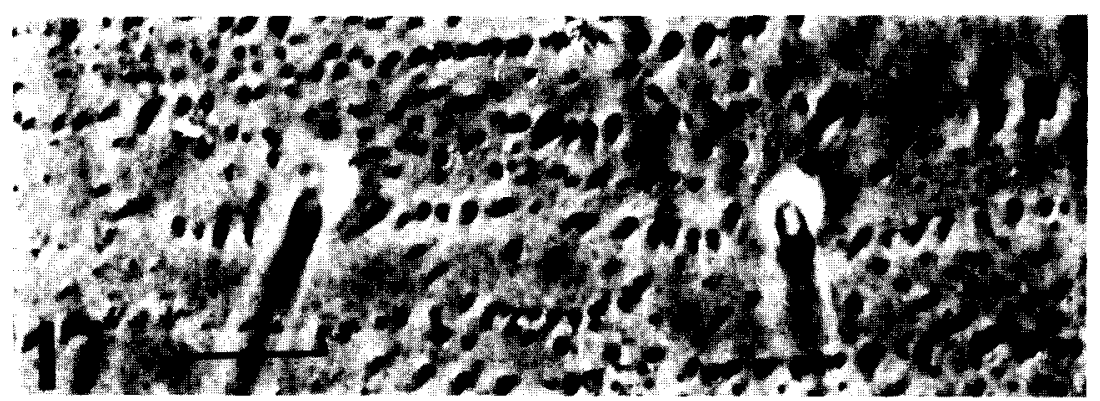

Fig. 17. The borderline cuticle between areas of tubercled cuticle (cf. Fig. 4 ) and smooth cuticle (Fig. 2) normally present on the adult sternites. Note the similarity to intermediate cuticle formed by injection of small amounts of juvenile hormone (Fig. 10). $\times 1400$; scale $=10 \mu$.

whose structure is reminiscent of that formed by tergal cells after injection of small amounts of the hormone (Fig. 10). Indeed it would seem that intermediate cells, or mosaics of two cell types, can be formed whenever developmental instructions are equivocal.

The phenomenon of intermediate cells shows that two alternative cellular states of differentiation need not be mutually exclusive (cf. Wilde, 1961). In Oncopeltus different features of the integument become insensitive to effective doses of juvenile hormone progressively, and there is cell-individual variation in the response when the hormone is near threshold level. Thus the process of determination and differentiation of epidermal cells is a gradual one-for example, in the chick limb bud where Searls (1967) has shown that initial differentiation of cartilage (detected by increased uptake of sulfate) precedes 
determination (assayed by transplantation into another area of the pattern).

\section{Effects of Juvenile Hormone on Hair Development}

Bristle pattern has long been recognized as a relatively simple twodimensional expression of the field phenomenon and for this reason has been subject to a considerable amount of experimental attack and theoretical speculation (Wigglesworth, 1940a; Stern, 1954; Claxton, 1964; Rendel, 1967). The sensitivity of hair development in Oncopeltus to juvenile hormone makes it particularly promising experimental material.

When $1.25 \mu \mathrm{g}$ of juvenile hormone was injected at between 27 and 49 hours, it had an overall and uniform effect on hair density in any one insect. Injection at 27 hours caused in one insect a reduction in hair number from about 3000 to 27 , and other insects with a complete range of intermediate hair numbers were found. It is most striking that the effect was not the random removal of hairs from the pattern, as was induced by mitomycin treatment, but was as if there were a limitation of the normal process of hair initiation. The development of these hairs occurs only in the metamorphic molt and consists of the transformation of spaced epidermal cells into hair mother cells. There follows three special differentiative divisions of each of these cells to give four cells, one of which soon degenerates. The 3-cell stages, which are formed asynchronously, accumulate, and later function synchronously in the secretion of the hair (Lawrence, 1966b). At which phase of this procedure does the juvenile hormone act?

Two lines of evidence show that the effect is not one of simple interference with the differentiative divisions or any later stage. First, earlier work had shown that when adult sternal tissue was grafted back onto a 3rd-stage larva, adult hairs developed on the graft during the molt of the host from 4th-stage to 5th-stage larva. The hairs developed on the central part of the graft which had undergone little reversal of metamorphosis (Lawrence, 1966a). The development of the host into a normal 5th-stage larva is witness to the effective presence of the juvenile hormone: thus neither the differentiative divisions nor hair maturation is inhibited directly by the hormone. Second, juvenile hormone injected at 74 hours (when the differentiative divisions are just beginning) or later has no effect on hair formation, and even at 64 hours the average effect of injection is very small. Conversely, mito- 
mycin injected at this time can cause complete inhibition. The possibility that changes in the length of the metamorphic molt, induced by potent doses of hormone, might define the period available for hair determination and therefore the number of hairs developing can also be eliminated. When juvenile hormone was applied topically in small amounts, or if only $0.06 \mu \mathrm{g}$ was injected, the molting time was not affected and the insects molted into individuals which appeared to be adults. Closer examination of the integument revealed patches of larval or intermediate cells. Wherever the integument was larval by other criteria, the hairs were lacking. The effect of juvenile hormone on hair development is thus local and direct and not dependent on the molting time of the whole insect.

It must therefore be concluded that the hormone acts prior to the differentiative divisions. The process of bristle determination has been studied by Wigglesworth (1940a) and a model proposed to describe the dynamic situation. Wigglesworth found that the bristles of Rhodnius were evenly spaced and that determination and development of new bristles depended on the number of cells present between extant bristles. (Both bristles and hairs of Oncopeltus are likewise evenly spaced and their number is dependent on the number of cells (Lawrence, 1966b). He suggested that a diffusible substance essential to the formation of bristles might be distributed uniformly throughout the epidermis and he required and absorbed by extant bristles and be essential for the initiation of new bristles. It must, also be supposed that the epidermal cells, which evidently produce this substance, can respond to a threshold concentration by becoming determined as bristles and rapidly absorb the substance, thereby inhibiting further determinations in their vicinity. At each molt in Rhodnius the number of cells increases, thereby upsetting the equilibrium and leading to the accumulation of substance and consequent further determinations at sites remote from extant bristles; this process continuing until the substance is absorbed as fast as it is produced and equilibrium is reestablished.

The significance of the fact that determination only occurs during a specific phase of the molt cycle has been overlooked. In Rhodnius (Wigglesworth, 1940a) and Oncopeltus (Lawrence, 1966b) determination of bristles is not immediately induced by the increase in cell number, for it does not occur during these mitoses but after the next ecdysis. Likewise during the development of hairs in Oncopeltus, 
determination and development of hairs occurs only after the proliferative cell divisions (Lawrence, 1966b).

Thus in the case of bristles in Oncopeltus or Rhodnius, the extent of determination is potentiated by the amount of earlier cell divisions. In the development of bristles there are therefore four phases: potentiation (the increase in the number of cells which effectively raises the amount of bristle-forming substance), determination (bristle cells are singled out as they respond to the increased substance and equilibrium is reestablished), differentiative divisions, and synthesis of the bristle structures. Potentiation and determination may be well separated in time, and this implies that areas of cells competent to form bristles are defined before the process of detcrmination begins. It is quite possible that, within those competent areas, each cell has an equal chance of becoming a new bristle (Fig. 18).

(1) 5th-stage larva, before cell divisions but after bristle determination.

(2) Early 5th-stage larva. Cell divisions in the 4th-stage larva have increased the number of cells between bristles and therefore the effective concentration of substance. There is now a region (shaded) in which brislle delermination can occur at random at the appropriate time. Two bristles are initiated (arrows) and rapidly absorb the substance, thus altering the landscape of substance concentration to give situation (3).

(4) The process of cellular metamorphosis then occurs; its effect is to lower the threshold to level $b$. If $1.25 \mu \mathrm{g}$ of juvenile hormone is injected during this period (0-64 hours after ecdysis) cellular metamorphosis is inhibited uniformly and the threshold may fall only to, say, level $a$. (When only $0.06 \mu \mathrm{g}$ of juvenile hormone is injected, the threshold is lowered to widely different levels in different cells and the result is very uneven hair distribution.) Hair determination begins at about 70 hours and two arrows mark the first sites. Initiation at these sites is immediately followed by absorption of the substance, resulting in the situation at $(5)$.

(5) This pattern is the final pattern for threshold level $a$, but further determinations occur at the threshold level $b(6)$ to produce the final pattern (7).

This system requires that the pace in which new centers arise within a competent field (the area above threshold) is slow compared to the speed of alteration in the distribution of substance concentration which these new centers induce. This pattern is produced in the same way as Claxton's simulation and is comparable to natural patterns (Claxton, 1964).

In Oncopeltus, the new hairs are incorporated into the bristle pattern, their number is affected by the number of cells and they are equivalent to the bristles in the pattern. However, the increase in cell number during the last molt in Oncopeltus cannot alone be responsible for potentiating the development of the hairs, for, in the studied area, 

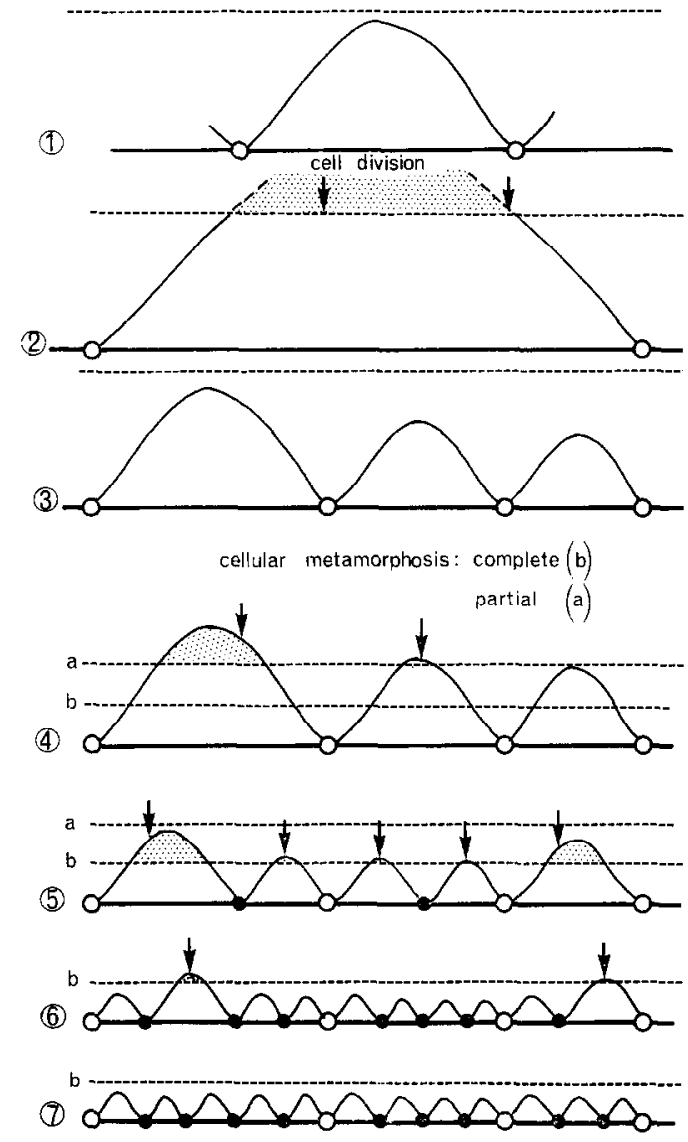

FIG. 18. The Wigglesworth model. The sequence of events during bristle and hair determination. The basal lines represent a series of sections through a developing pattern. The dashed lines represent the threshold of response of the cells to the amount of diffusible substance (curved lines) which is absorbed by extant bristles (empty circles) and hairs (filled circles).

the number of hairs and bristles increases about twenty times, whereas the cell number approximately doubles (Lawrence, 1968). The process of hair determination follows the main mass of proliferative divisions and therefore begins at about 70 hours (Lawrence, 1966b). However the hair number is affected only by injection of juvenile hormone (Fig. 13) before 64 hours, and hairs are completely suppressed only if the injection is performed immediately after the ecdysis. Thus the effect 
of juvenile hormone is not directly on the ongoing process of hair determination, but must be on the potentiation of that process. What is the nature of this potentiation? It must involve a change in one of the variables in the Wigglesworth model: Either the rate of substance production by the epidermal cells could be increased, or the threshold level of the cells could drop. Either or both these changes could be the result of cellular metamorphosis and sensitive to juvenile hormone. In the former case any localized pocket of adult cells would produce more substance; this would diffuse out and enhance development beyond the borders of the adult island. In the latter case the expression of hair density in patches of metamorphosed cells would be autonomous. Insects which do have just such patches of metamorphosed cells (as detected by pigmentation and microsculpture of the cuticle) have been experimentally produced by topical application of the juvenile hormone (Fig. 19), and by injection of small amounts. Clearly the distribution of hairs is uneven, and patches of hairs of

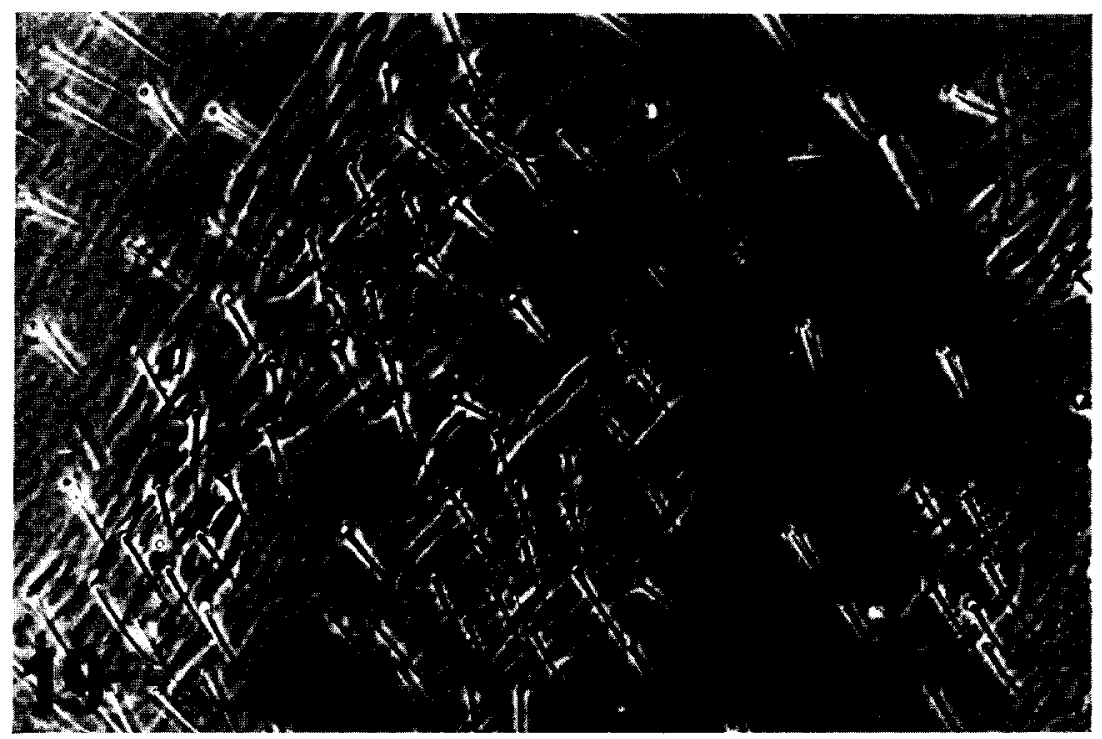

FIG. 19, Hair distribution in a mosaic insect induced by topical application of juvenile hormone. The adult patches are dark and bear little rows of tubercles. It can be seen that the hair distribution is uneven, there being many more hairs in the adult patches than in the larval surround. $X 220$; scale $=100 \mu(t$, tubercles; $a$, adult patch). 
high density are found wherever the presence of adult pigment indicates adult cells. Thus the expression of hair density is autonomous to the more adult patches, and does not spread out evenly, and therefore, within the terms of the Wigglesworth model, the effect of normal metamorphosis is to lower the threshold of the cells, rather than to increase the rate of substance production. The establishment of this threshold is sensitive to juvenile hormone from the beginning of the 5th-stage until about 64 hours.

The continuous range in hair densities in intermediates suggest that this threshold can be fixed at any level between those of potential adults and larvae. The development of high densities of adult hairs in an otherwise larval integument suggests that this threshold becomes fixed earlier than the factors determining cuticular structure. The metamorphosis of insect epidermal cells is here seen as a gradual one, with different features of the larval cells becoming transformed at different times.

Thus, in conclusion, one effect of metamorphosis on the epidermal cells of Oncopeltus would seem to make them more responsive to the hair-promoting substance but not change the amount of such substance. The change, as in nearly all the bristle mutants of Drosophila examined by Stern and his school (Arnheim, 1967) is in the "competence" rather than the "prepattern" (Stern, 1954). This change of threshold, like other changes in the cells, is promoted in the absence of juvenile hormone, and halted or reversed in its presence. The development of a small or intermediate number of uniformly spaced hairs can thus be an indicator of a limited amount of cellular metamorphosis which does not otherwise find expression.

Further evidence for the applicability of the Wigglesworth model to bristle and hair development in Oncopeltus arises from the work of Claxton (1964). With regard to the requirements of the Wigglesworth model he constructed patterns of units showing regularity in spacing. He entered points at random on paper, drew an inhibitory circle around each point, and discarded any further points that fell within these circles. Eventually there was no space left for further points. Claxton found that the spatial distribution of the points in any completed pattern as measured by the scalar number $R$ (cf. page 25) was related to the variance in the sizes of the inhibitory circles drawn around each point and to the coefficient of variation of nearestneighbor distances (Fig. 20). The distribution of hair follicles of sheep 


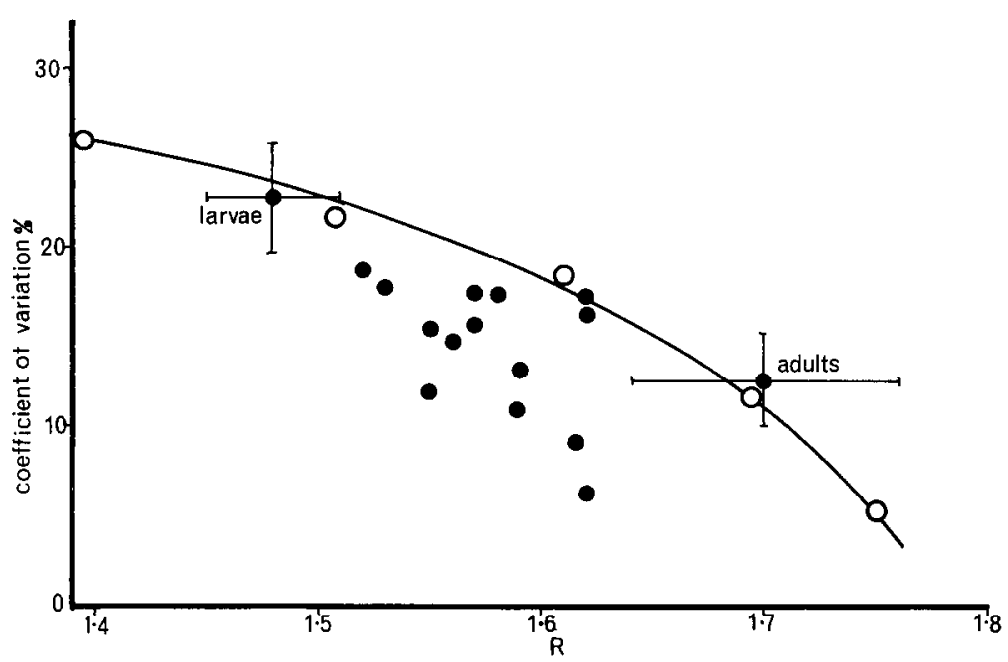

Fig. 20. Claxton's simulation. The open circles are taken from Claxton (1964) and represent the relationship between the coefficient of variation of nearestneighbor distances, and the measure of uniformity of distribution, $R$, in various patterns he constructed with regard to the tenets of the Wigglesworth model. The distribution of hairs and bristles in Oncopeltus larvae and adults coincide with the curve, showing that their patterns could have been constructed in an equivalent way. There seems to be a slight, but significant, departure from the curve by the 14 intermediates (filled circles). The vertical and horizontal lines demarcate two standard deviations.

and bristles of Drosophila conformed with this relationship, and could, therefore, be generated by a similiar mechanism. I measured the coefficient of variation of nearest-neighbor distances and the distribution of hairs and bristles in 5th-stage larvae and adults of Oncopeltus. Figure 20 shows that these results also conform with Claxton's simulation.

Some intermediates were also analyzed in this way, and there would seem to be a significant departure from the curve, most points lying well below it. This implies that some restriction not active in Claxton's simulation is affecting intermediates. One possible explanation is that the pattern is not quite completed; there are still some spaces left where points could be added. This would have a large affect on $R$, without influencing the nearest-neighbor measurements much, and the points would therefore be displaced considerably from the expected line. Thus in addition to the major effect of juvenile 
hormone on the hair density there may be a very slight effect, perhaps because of the curtailed molt cycle, which cuts short hair determination just before equilibrium has been reached.

\section{SUMMARY}

The integument of Oncopeltus is very different in larvae and adults, and the transformation is sensitive to juvenile hormone. The effects of a synthetic juvenile hormone analog on cellular metamorphosis (here regarded as an example of cellular differentiation) were analyzed at two levels:

\section{A. Effects on cuticle secreted by individual cells}

1. Potent doses (1.25 $\mu \mathrm{g}$ of the crude extract) when injected early in the last molt of Oncopeltus caused complete inhibition of metamorphosis and curtailed the molt cycle.

2. After injection of the same dose at 27 and 49 hours after ecdysis, larval cuticle was formed; but injection at 64 and 74 hours produced a series of adult/larval intermediate insects whose abdominal integument consisted of intermediate cells. The whole insect was affected and the epidermal cells responded uniformly. A continuous series of integuments showing increasing cellular metamorphosis was obtained.

3. When threshold doses $(0.06 \mu \mathrm{g})$ of the hormone were injected early in the molt, only the epidermis was affected and the response of the epidermal cells was heterogeneous, resulting in mosaic insects.

\section{B. Effects on the hair pattern}

During metamorphosis in Oncopeltus evenly spaced hairs develop. These structures are distinct from, and much denser than, the larval bristles. Their development is sensitive to the juvenile hormone.

1. Injection of potent doses of juvenile hormone within a few hours of the previous ecdysis completely suppressed hair development. After this time and up until 64 hours after ecdysis hair development was only partially reduced, even though the cuticle secreted was completely larval by other criteria. There was no effect on hair density after 64 hours, even though the visible cytological events associated with hair differentiation do not begin until 70 hours.

2. The intermediates could be arranged in a continuous series of increasing hair density. The uniformity of distribution was measured quantitatively and found to improve with density. 
3. Mitomycin $\mathrm{C}$ was injected and found to disrupt hair development independently from juvenile hormone, probably by direct interference with hair development.

4. The hair and bristle pattern was analyzed quantitatively according to the method of Claxton (1964): the results supported the adoption of the Wigglesworth model for bristle development as a working hypothesis. Within the terms of this model, the juvenile hormone was shown to maintain the threshold of epidermal cells to the bristle-forming substance, a threshold which falls during normal cellular metamorphosis.

5. The process of cellular metamorphosis and differentiation in this system is considered to be a gradual one, which can be halted by juvenile hormone. The development of small numbers of evenly spaced hairs in intermediates is regarded as an expression of partial metamorphosis or differentiation.

I thank Professors D. Bodenstein, M. Locke, H. A. Schneiderman, and J. M. Thoday for accommodation and encouragement received in their laboratories; and the Commonwealth Fund, grants from the National Science Foundation (GB4847X) and U. S. Public Health Service (GM09960) awarded to Professors Bodenstein and Locke, respectively, and the Agricultural Research Council for financial support. Professor C. M. Williams kindly gave me the synthetic juvenile hormone, and Dr. A. D. Lees, F.R.S., and Murray Pearson have read and criticized the manuscript. I thank Dr. G. C. Webster for helpful discussion.

\section{REFERENCES}

ArNheim, N. (1967). The regional effects of two mutants in Drosophila analyzed by means of mosaics. Genetics 56, 253-263.

Clark, P. J., and Evans, F. C. (1954). Distance to nearest neighbour as a measure of spatial relationships in populations. Ecology 35, 445-453.

Claxton, J. H. (1964). The determination of patterns with special reference to that of the central primary skin follicles in sheep. J. Theoret. Biol. 7, 302-317.

GrobsteIs, C. (1959). Differentiation of vertebrate cells. In "The Cell" (J. Brachet and A. E. Mirsky, eds.), Vol. I, pp. 437-496. Academic Press, New York.

Himdreth, P. E. (1965). Doublesex, a recessive gene than transforms both males and females of Drosophila into intersexes. Genetics 51, 659-678.

Hollingsworth, M. J. (1964). Sex-combs of intersexes and the arrangement of the chaetae on the legs of Drosophila. J. Morphol. 115, 35-52.

Krishnakumaran, A., Berry, S. J., Oberlander, H., and Schnemeraman, H. A. (1967). Nucleic acid synthesis during insect development. II. Control of DNA synthesis in the Cecropia silkworm and other saturniid moths. J. Insect Physiol. 13, 1-57. 
Law, J. H., Yuan, C., and Williams, C. M. (1966). Synthesis of a material with high juvenile hormone activity. Proc. Natl. Acad. Sci. U. S. 55, 576-578.

LAwRENCE, P. A. (1966a). The hormonal control of the development of hairs and bristles in the milkweed bug, Oncopeltus fasciatus, Dall. J. Exptl. Biol. 44, 507-522.

Lawrence, P. A. (1966b). Development and determination of hairs and bristles in the milkweed bug, Oncopeltus fasciatus (Lygaeidae, Hemiptera). J. Cell Sci. 1, 475-498.

Lawrence, P. A. (1967). The insect epidermal cell-"A simple model of the embryo." In "Insects and Physiology" ( J. W. L. Beament and J. E. Treherne, eds.), pp. 53-68. Oliver \& Boyd, Edinburgh and London.

Lawrence, P. A. (1968). Mitosis and the cell cycle in the metamorphic moult of the milkweed bug Oncopeltus fasciatus. A radioautographic study. J. Cell Sci. 3, 391-404.

LEEs, A. D. (1942). Homology of the campaniform organs on the wing of Drosophila melanogaster. Nature 150, 375.

LüöND, H. (1961). Untersuchungen zur Mustergliederung in fragmentieren Primordien des männlichen Geschlechtsapparates von Drosophila seguyi. Develop. Biol. 3, 615-656.

Marcus, W. (1962). Untersuchungen über die Polarität der Rumpfhaut von Schmetterlingen. Roux' Arch. Entwicklungsmech. Organ. 154, 56-102.

Novík, V. J. A. (1951). The metamorphosis hormones and morphogenesis in Oncopeltus fasciatus Dal. Mém. Soc. Zool. Tchécosl. 15, 1-47.

PıEPHo, H. (1939). Raupenhäutungen bereits verpuppter Hautstïcke bei der Wachsmotte Galleria mellonella L. Naturwissenschaften 27, 301-302.

Piepho, H., and Heims, A. (1952). Das Kutikularmuster der Schmetterlingslarve und die hormonale Grundlage seiner Entstehung. Untersuchungen an der Wachsmotte Galleria mellonella L. Z. Naturforsch. 7b, 231-237.

PiePHO, H., and MeYER, H. (1951). Reaktionen der Schmetterlingshaut auf Häutungshormone. Biol. Zentr. 70, 252-260.

Rendel, J. M. (1967). "Canalisation and Gene Control." Logos Press; Academic Press, New York and London.

RomaŇUk, M., Sláma, K., and ŠORM, F. (1967). Constitution of a compound with a pronounced juvenile hormone activity. Proc. Natl. Acad. Sci. U. S. 57, 349-352.

Schnemerman, H. A., and Gilbert, L. I. (1958). Substances with juvenile hormone activity in Crustacea and other invertebrates. Biol. Bull. 115, 530-535.

SEARLS, R. L. (1967). The role of cell migration in the development of the embryonic chick limb bud. J. Exptl. Zool. 166, 39-50.

Sehnal, F., and Nováx, V. J. A. (1968). "Proc. Intern. Congr. Insect Endocrinol. Brno 1966." Academic Press, New York. In press.

SeIler, J. (1965). Sexuality as a developmental process. Proc. 2nd Intern. Congr. Genetics, Genetics Today 2, 199-207.

Stern, C. (1954). Two or three bristles. Am. Sci. 42, $213-247$.

Sters, C. (1967). Pigmentation mosaicism in intersexes of Drosophila. Rev. Suisse Zool. 73, 339-355. 
Stern, C., and MukherjeE, A. S. (1964). Aspects of the developmental genetics of the legs of Drosophila. Proc. Natl. Acad. Sci. India, Symp. volume on growth and regeneration $34 \mathrm{~B}, 19-26$.

Wicclesworth, V. B. (1934). The physiology of ecdysis in Rhodnius prolixus (Hemiptera). II. Factors controlling moulting and 'metamorphosis.' Quart. J. Microscop. Sci. 77, 191-222.

Wigglesworth, V. B. (1936). The function of the corpus allatum in the growth and reproduction of Rhodnius prolixus (Hemiptera). Quart. J. Microscop. Sci. 79, 91-121.

Wigglesworth, V. B. (1940a). Local and general factors in the development of "pattern" in Rhodnius prolixus (Hemiptera). J. Exptl. Biol. 17, 180-200.

Wiggleswonth, V. B. (1940b). The determination of characters at metamorphosis in Rhodnius prolixus (Hemiptera). J. Exptl. Biol. 17, 201-222.

Wiggiesworth, V. B. (1942). Some notes on the integiment of insects in relation to the entry of contact insecticides. Bull. Entomol. Res. 33, 205-229.

Wiggleswonth, V. B. (1953). The origin of sensory neurones in an insect, Rhodnius prolixus (Hemiptera). Quart. J. Microscop. Sci. 94, 93-112.

Wigglesworth, V. B. (1961). Some observations on the juvenile hormone effect of farnesol in Rhodnius prolixus Stål (Hemiptera). J. Insect Physiol. 7, 73-78.

Wilde, C. E. (1961). The differentiation of vertebrate pigment cells. Advan. Morphogenesis 1, 267-300. 